\title{
Phytoprotection
}

phytoprotection

\section{Index des sujets}

Volume 85, numéro 3, décembre 2004

URI : https://id.erudit.org/iderudit/010910ar

DOI : https://doi.org/10.7202/010910ar

Aller au sommaire du numéro

Éditeur(s)

Société de protection des plantes du Québec (SPPQ)

ISSN

0031-9511 (imprimé)

1710-1603 (numérique)

Découvrir la revue

Citer cet article

(2004). Index des sujets. Phytoprotection, 85(3), 171-172.

https://doi.org/10.7202/010910ar d'utilisation que vous pouvez consulter en ligne.

https://apropos.erudit.org/fr/usagers/politique-dutilisation/ 
Index des sujets, volume 85

Subject Index, Volume 85

\section{A-B}

Abutilon theophrasti

Accouplements hors agrégat

Accouplements locaux

Actinomycètes / actinomyces

Aircraft

Altérations pariétales

Ancient resistance

Apposition pariétale

Avion

Barley yellow dwarf virus

Barley

Beneficial insects

Bibliothèque génomique

Biodiversité / biodiversity

Biofertilisants

Biofongicides

Bio-informatique / bioinformatics

Biological control

Biological fertilizer

Biological fungicides

Blé

Bluestain fungus

BMV

Botrytis cinerea

BSMV

BYDVs

\section{C}

Canola / canola

Carie chez les arbres

Carnation

Carotte / carrot

Caterpillars

cDNA library

Centre Sève

Cereal viruses

Champignon de bleuissement

Champignons endophytes

Champignons mycorhiziens

Champignons pathogènes

Chenilles

Chitine / chitin

Chitosane / chitosan

Chromosomes / chromosomes

Comparative genomics

Control

Contrôle de la croissance

Corps crystallins

Croisements

Croissance des racines

Croissance des tiges

Crop rotation

Cultures tolérantes aux herbicides CYDV-RPV

\section{D-F}

Date du semis $\quad 161$

Decay in trees 68

Degrés-jours / Degree-days 54

Désherbage 55

Dutch elm disease 39, 53

Éliciteurs / elicitors 33

Endophytic fungi 59

Engrais phosphatés 4

Enzymes salivaires 33

Épidémiologie / epidemiology $\quad 45$

Étiquette 39

Expressed sequence tag 39

Faba beans $\quad 89$

Farm manure $\quad 58$

Féverole $\quad 89$

Flétrissement 121, 139

Forest exotic pest 58

Fraise $\quad 81$

Fumiers 58

Fungal walls 121, 139

Fungal wilt 121,139

Fungi $\quad 81$

Fusarium 56

F. graminearum 58

F. oxysporum f.sp. dianthi 121, 139

F. verticillioides $\quad 67$

\section{G-I}

Gale commune 56

Génomique / genomics 39

Génomique comparative $\quad 45$

Germination / germinability $\quad 161$

Glyphosate / glyphosate $\quad 95$

Greeenhoouse tomato 59

Growth control 67

Herbicide resistant crops $\quad 55$

Herbicide séquentiel 95

Herbicides de postlevée 153

Host cell wall alterations $\quad 121,139$

Identification moléculaire 56

Insectes utiles 69

Insectes zoophytophages $\quad 71$

Interactions plantes-insectes 33

Invasive alien plants 5

lodine-based pesticide $\quad 67$

Ionisation / ionization $\quad 81$ 


\section{L-O}

Leaf rust

Leptinotarsa decemlineata

Liquid manure

Lisiers

Lutte biologique

Lycopersicum esculentum

Maladie hollandaise de I'orme

Maladies des plantes

Marking techniques

Mauvaises herbes

Medicago truncatula

Meloidogyne hapla

Microhyphes / microhyphae

Moisissures

Molecular identification

Multiple disease resistance

Multirésistance aux maladies

Mycorrhizal fungi

Nématodes / nematodes

Non-invasive acoustic tool

Fillet

Off-patch mating

Oïdium

On-patch mating

Ophiostoma

O. novo-ulmi

Orge

Outil acoustique non destructif

Ozone / ozone

\section{$\mathbf{P}$}

Paracrystalloids

Parasitic fitness

Parois fongiques

Pathogenic fungi

Pathogénicité / pathogenicity

Pesticide à base d'iode

Phénols / phenols

Phosphorus fertilization

Physiological stress

Phytophthora nicotianae

Picea glauca

Plant disease

Plant protection

Plantes exotiques envahissantes

Planting date

Plant-insect interactions

Postemergence herbicides

Powdery mildew

Pratylenchus penetrans

Protection des plantes

Protéomique / proteomics

Pythium ultimum

\section{R-S}

Ravageurs forestiers exotiques 58

Répression 57

Résistance / resistance 89

Résistance ancienne 49

Root growth 153

Rotation des cultures 13

Rouille des feuilles $\quad 27$

Salivary enzymes 33

Sclerotinia trifoliorum 89

Scolytidae 53

Seedling vigour $\quad 161$

Séquençage / sequencing 39

Sequential herbicides $\quad 95$

Shoot growth 153

Soja / soybean $\quad 95$

Spodoptera exigua 33

Strawberry $\quad 81$

Streptomyces

S. coelicolor

S. melanosporofaciens 53, 56

S. scabies 56

Stress physiologique $\quad 59$

T-Z

Tapissement des parois vasculaires 121, 139

Techniques de marquage 69

Thinopyrum 27

Tomate de serre $\quad 59$

Trichogramma evanescens 70

Trifolium pratense 153

Ulmus americana 53

Ustilago nuda

Valeur adaptative 39

Vessel wall coating 121, 139

Virus de la jaunisse nanisante de l'orge 27

Virus des céréales $\quad 19$

Vitalité des plantules $\quad 161$

Wall apposition $\quad 49$

WDV 19

Weed control $\quad 55$

Weeds 4,5

Wheat 19,27

Wide crosses 27

$\begin{array}{ll}\text { Zoophytophagous insects } & 71\end{array}$ 